\title{
The COVID-19 Outbreak and Psychological Distress in Healthcare Workers: The Role of Personality Traits, Attachment Styles, and Sociodemographic Factors
}

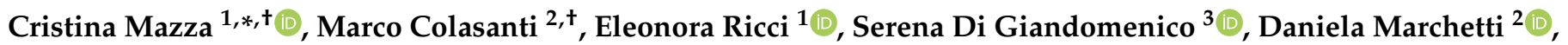 \\ Lilybeth Fontanesi $^{2}{ }^{(\mathbb{D}}$, Maria Cristina Verrocchio ${ }^{2}$, Stefano Ferracuti ${ }^{4}$ and Paolo Roma $^{4}{ }^{(\mathbb{D}}$ \\ 1 Department of Neuroscience, Imaging and Clinical Sciences, G. d'Annunzio University of Chieti-Pescara, \\ 66100 Chieti, Italy; eleonoraricci25@gmail.com \\ 2 Department of Psychological, Health and Territorial Sciences, G. d'Annunzio University of Chieti-Pescara, \\ 66100 Chieti, Italy; marco.colasanti@hotmail.com (M.C.); d.marchetti@unich.it (D.M.); \\ lilybeth.fontanesi@unich.it (L.F.); mc.verrocchio@unich.it (M.C.V.) \\ 3 Department of Humanities, University of Urbino Carlo Bo, 61029 Urbino, Italy; serenadigiando@gmail.com \\ 4 Department of Human Neuroscience, Sapienza University of Rome, 00185 Rome, Italy; \\ check for \\ Citation: Mazza, C.; Colasanti, M.; \\ Ricci, E.; Di Giandomenico, S.; \\ stefano.ferracuti@uniroma1.it (S.F.); paolo.roma@uniroma1.it (P.R.) \\ * Correspondence: cristina.mazza@unich.it \\ + Authors contributed to the paper equally.
}

Marchetti, D.; Fontanesi, L.;

Verrocchio, M.C.; Ferracuti, S.; Roma, P. The COVID-19 Outbreak and Psychological Distress in Healthcare Workers: The Role of Personality Traits, Attachment Styles, and Sociodemographic Factors. Sustainability 2021, 13, 4992. https: / / doi.org/10.3390/ su13094992

\section{Academic Editors:}

Emanuele Cannizzaro,

Tiziana Ramaci,

Massimiliano Barattucci and Fulvio Plescia

Received: 12 March 2021

Accepted: 26 April 2021

Published: 29 April 2021

Publisher's Note: MDPI stays neutral with regard to jurisdictional claims in published maps and institutional affiliations.

Copyright: (c) 2021 by the authors. Licensee MDPI, Basel, Switzerland. This article is an open access article distributed under the terms and conditions of the Creative Commons Attribution (CC BY) license (https:// creativecommons.org/licenses/by/ $4.0 /)$.

\begin{abstract}
The COVID-19 outbreak has exposed healthcare professionals (HPs) to increased workloads and a high risk of contagion. The present study aimed at examining the effects of the COVID-19 outbreak on the mental health of HPs in Italy, investigating the role of attachment style, personality traits, and sociodemographic variables. An online survey was administered from 18 to 22 March 2020. Respondents were 296 HPs (77\% female, 23\% male; aged 21-77 years). The measures employed were a sociodemographic questionnaire, the Personality Inventory for DSM-5-BF (PID-5-BF), the Attachment Style Questionnaire (ASQ), and the Depression, Anxiety and Stress Scale-21 (DASS-21). The findings showed that PID-5-BF Negative Affect, female gender, and ASQ Preoccupation with Relationships predicted high levels of stress, anxiety, and depression, respectively. Furthermore, PID-5-BF Detachment predicted higher psychological distress, as captured in the DASS-21 total score and DASS-21 Depression score, and having an infected loved one was associated with high psychological distress. Overall, the results suggest that HPs are experiencing high rates of psychological distress during the pandemic, and that specific attachment styles and personality traits might be useful in identifying those at greatest risk for developing mental health symptoms.
\end{abstract}

Keywords: healthcare workers; psychological factors; attachment style; personality traits; mental health; COVID-19; ASQ; PID-5-BF; DASS-21

\section{Introduction}

On 30 January 2020, the World Health Organization declared the coronavirus disease 2019 (COVID-19) outbreak a public health emergency of international concern. Many governments issued exceptional measures to reduce the spread of the virus, including lockdowns, curfews, and social distancing [1]. According to the literature [2-5], the ongoing pandemic and its related protective measures have had a negative impact on the mental health of the general population, in the form of increased psychological distress, depression, anxiety, and post-traumatic stress symptoms, as well as sleep disturbance, parental exhaustion, and suicidality. Researchers have sought to identify factors associated with negative mental health outcomes during the pandemic. While some studies have yielded contradictory results, a recent meta-analysis indicated that female gender, younger age, lower socioeconomic status, rural residency, and a history of specific medical conditions 
are associated with an increased likelihood of experiencing psychological distress during this time [6].

While most of the relevant studies have focused on the impact of the COVID-19 pandemic on the mental health of the general population, some research has specifically examined the effects of the pandemic on specific populations (e.g., parents, psychiatric patients, overweight/obese individuals) [7-9]. For instance, a recent systematic review found that COVID-19 patients showed high levels of post-traumatic stress symptoms and higher depressive symptoms relative to the general population [9]. Moreover, patients with pre-existing psychiatric disorders have reported a worsening of psychiatric symptoms during the pandemic. Further, Mazza et al. found that certain personality traits represented important risk factors for parents' mental health difficulties during the lockdown [7]. Specifically, the authors found that parental neuroticism was significantly associated with parental distress, which was also related to children's emotional and behavioral difficulties. Furthermore, high levels of parent neuroticism (i.e., worry, nervousness, emotional instability, etc.) were found to increase parent psychological distress, mainly in terms of anxiety, depression, and social dysfunction.

Among these specific populations, healthcare professionals (HPs), who are identified in Italy as professionals who are authorized by the State to conduct activities involved in prevention, diagnosis, cure, and rehabilitation [10] (http:/ / www.salute.gov.it/portale/temi/ p2_4.jsp?lingua=italiano\&area=professioni-sanitarie. Accessed on 15 December 2020), represent frontline workers who are faced with the greatest and most direct exposure to COVID-19. Attention to HPs is warranted given their increased workload and high risk of contagion, representing risk factors for not only physical health, but also mental well-being (see [9] for a systematic review). On this matter, the literature reports high psychological distress among HPs during the COVID-19 pandemic, especially among nurses, females, younger medical staff, and frontline workers [11-14].

Of note, perceived danger triggers the attachment motivational system; it is a common conception that adults with a secure attachment style are generally more resilient in stressful situations, demonstrating adaptive coping strategies [15,16]. In support of this view, international research has found that secure attachment protects against the development of post-traumatic stress symptoms $[17,18]$, and insecure attachment relates to increased perceived stress, somatization, and negative affectivity [18-20]. With respect to HPs, the role of attachment style in situations of prolonged stress or trauma is under-investigated. A single review indicated that secure attachment and anxious-preoccupied attachment are associated with lower and higher levels of burnout, respectively [21]. Similarly, research has found that fearful-avoidant attached nurses report significantly higher levels of job-related stress compared to nurses with secure attachment [22,23]. However, another study yielded more ambiguous results: on the one hand, securely and insecurely attached hospice nurses were found to show no differences in the frequency of stressful experiences or number of psychological components of ill health; on the other hand, the two groups differed in the number of absences from work and the frequency with which they sought social support [24].

In general, there is insufficient research on the relationship between attachment style and mental health during the COVID-19 pandemic. Moccia et al. reported that features of both secure and avoidant attachment, compared to those of anxious attachment, protected against higher psychological distress [25]. Starting from these results, the present study aimed at investigating the effect of attachment style, personality dysfunction, and sociodemographic variables on mental health in HPs during the COVID-19 pandemic.

\section{Materials and Methods}

\subsection{Participants}

Data were collected through an online survey administered between 18 and 22 March 2020 to 337 respondents. The inclusion criteria were as follows: (a) aged 18 years or older, (b) living in Italy, and (c) working as an HP. A total of 19 participants were excluded be- 
cause they were not working as an HP, 12 were excluded because they did not complete the survey, 6 were excluded because they lived outside of Italy, and 4 were excluded because they did not provide informed consent. Thus, the final sample consisted of 296 Italian participants: 228 (77\%) women and $68(23 \%)$ men. The mean age of the sample was 38.89 years (12.32; range 21-77). More descriptive statistics, including all of the characteristics considered, are presented in Table 1. In Table S1 (Supplementary Materials), means and standard deviations for all the scales (i.e., DASS-21, ASQ, and PID-5-BF) computed considering the whole sample are presented.

Table 1. Descriptive statistics of the sample.

\begin{tabular}{|c|c|c|}
\hline Characteristic & Group & $n(\%)$ \\
\hline \multirow{2}{*}{ Gender } & Female & $228(77 \%)$ \\
\hline & Male & $68(23 \%)$ \\
\hline Age $M(S D)$, Min-Max & 38.89 (12.32), 21-77 & $296(100 \%)$ \\
\hline \multirow{2}{*}{ Employment status } & Employee & $140(47.3 \%)$ \\
\hline & Freelancer & $156(52.7 \%)$ \\
\hline \multirow{3}{*}{ Education } & High school diploma & $13(4.4 \%)$ \\
\hline & Graduate & $129(43.6 \%)$ \\
\hline & Postgraduate & $154(52 \%)$ \\
\hline \multirow{10}{*}{ Occupation } & Social worker & $8(2.7 \%)$ \\
\hline & Doctor & $85(28.7 \%)$ \\
\hline & Pharmacist & $9(3 \%)$ \\
\hline & Physiotherapist & $16(5.4 \%)$ \\
\hline & Dental hygienist & $2(0.7 \%)$ \\
\hline & Nurse & $38(12.8 \%)$ \\
\hline & Speech therapist & $7(2.4 \%)$ \\
\hline & Psychologist/psychotherapist & $103(34.8 \%)$ \\
\hline & Social health worker & $7(2.4 \%)$ \\
\hline & Technician & $21(7.1 \%)$ \\
\hline \multirow{3}{*}{ Marital status } & Unmarried/widower & $142(48 \%)$ \\
\hline & Separated/divorced & $17(5.7 \%)$ \\
\hline & Married & $137(46.3 \%)$ \\
\hline \multirow{2}{*}{ Child(ren) in house } & Yes & $98(33.1 \%)$ \\
\hline & No & $198(66.9 \%)$ \\
\hline \multirow{3}{*}{ Region of residence } & North & $63(21.3 \%)$ \\
\hline & South & $150(50.7 \%)$ \\
\hline & Center & $83(28 \%)$ \\
\hline \multirow{2}{*}{ Spending social distancing period with } & With others & $248(83.8 \%)$ \\
\hline & Alone & $48(16.2 \%)$ \\
\hline \multirow{2}{*}{ Infected acquaintances } & Yes & $89(30.1 \%)$ \\
\hline & No & $207(69.9 \%)$ \\
\hline \multirow{2}{*}{ Infected loved ones } & Yes & $23(7.8 \%)$ \\
\hline & No & $273(92.2 \%)$ \\
\hline
\end{tabular}


Table 1. Cont.

\begin{tabular}{ccc}
\hline Characteristic & Group & $\boldsymbol{n}(\mathbf{\%})$ \\
\hline \multirow{2}{*}{ History of stressful situations } & Yes & $121(40.9 \%)$ \\
\cline { 2 - 3 } & No & $175(59.1 \%)$ \\
\hline \multirow{2}{*}{ History of medical problems } & Yes & $78(26.4 \%)$ \\
\cline { 2 - 3 } & No & $218(73.6 \%)$ \\
\hline \multirow{2}{*}{ Psychological support or psychotherapy } & Yes & $73(24.7 \%)$ \\
\cline { 2 - 3 } & No & $223(75.3 \%)$ \\
\hline
\end{tabular}

\subsection{Procedures}

The questionnaire was administered on an online survey platform, Qualtrics, which participants accessed via a designated link. The link was disseminated through the main means of communication and social networks, in order to reach a large number among all the healthcare professionals throughout Italy, during the social distancing and lockdown period. Participants voluntarily responded to the anonymous survey and indicated their informed consent within the survey, prior to providing feedback. Qualtrics automatically reports the IP code that we have used together with sociodemographic data to ensure that the survey was completed once by each participant. All procedures were clearly explained, and participants could interrupt or quit the survey at any point without explaining their reasons for doing so.

\subsection{Data Collection}

The online survey, which comprised part of a wider research project, covered several areas: (a) sociodemographic details; (b) acquaintances infected with COVID-19; (c) loved ones infected with COVID-19; (d) previous physical diseases (e.g., cardiovascular or oncological pathology); (e) previous stressful situations (e.g., dismissal, mourning); (f) psychological treatment or psychotherapy; (g) personality functioning; (h) attachment style; and (i) the psychological impact of COVID-19 on depression, anxiety, and stress levels over the past 7 days.

\subsubsection{Sociodemographic Data}

Sociodemographic data were collected on biological sex, age, education, marital and parental status, employment status, region of residence during the COVID-19 outbreak, and history of stressful situations and medical problems. Moreover, participants were asked to report whether any acquaintances or loved ones were (or had been) infected with COVID-19.

\subsubsection{Personality Dysfunction}

Personality functioning was investigated using the Personality Inventory for DSM-5-Brief Form-Adult (PID-5-BF) [26]. The PID-5-BF is a 25-item self-rated personality trait assessment scale, which measures five personality trait domains: negative affect (e.g., "I worry about almost everything"; "I get emotional easily, often for a small reason"), detachment (e.g., "I often feel like nothing I do matters"; "I steer clear of romantic relationships"), antagonism (e.g., "I don't like to get too intimate with people"; "I long for attention"), disinhibition (e.g., "People would describe me as reckless"; "I feel like I act completely on impulse"), and psychoticism (e.g., "I often have thoughts that make sense to me, but others say they're weird"; "Often things around me seem unreal, or more real than usual"). Each domain is measured through five items that are rated on a four-point Likert scale ranging from 0 (very false or often false) to 3 (very true or often true). The overall measure generates scores in the range of $0-75$, with higher scores indicating greater overall personality dysfunction. Furthermore, each trait domain receives a score in the range of $0-5$, with higher scores indicating greater dysfunction in that specific domain. In the Italian validation study [27], Cronbach's alpha values for the PID-5-BF scales ranged from 
0.59 (Detachment) to 0.77 (Psychoticism), and Cronbach's alpha for the PID-5-BF total score was 0.83 , showing good internal consistency. In the present sample, Cronbach's alpha values for the PID-5-BF scales ranged from 0.62 (Antagonism) to 0.71 (Disinhibition), and Cronbach's alpha for the PID-5-BF total score was 0.88 , again showing good reliability.

\subsubsection{Attachment Style}

The Italian version of the Attachment Style Questionnaire (ASQ) was used to evaluate attachment style [28]. The ASQ is a self-report instrument containing 40 items articulated in five subscales: Confidence (e.g., "Overall, I am a worthwhile person"; "I feel confident about relating to others"), Discomfort with Closeness (e.g., "I prefer to keep to myself"; "I worry about people getting too close"), Relationships as Secondary (e.g., "People's worth should be judged based on their success"; "Achieving things is more important than building relationships"), Need for Approval (e.g., "It's important to me that others like me"; "Sometimes I think I am no good at all"), and Preoccupation with Relationships (e.g., "I worry a lot about my relationships"; "I often feel left out or alone"). All subscales are rated on a six-point scale ranging from 1 (totally disagree) to 6 (totally agree). The ASQ obtained good reliability in the Italian validation study with a non-clinical sample [28], generating Cronbach's alpha values of 0.69 for Confidence, 0.68 for Discomfort with Closeness, 0.73 for Relationships as Secondary, 0.69 for Need for Approval, and 0.64 for Preoccupation with Relationships. However, in the present sample, the Confidence subscale obtained an unacceptable Cronbach's alpha (0.47); therefore, this scale was excluded from the analysis. All other ASQ subscales obtained good reliability, with Cronbach's alpha values of 0.62 for Discomfort with Closeness, 0.73 for Relationships as Secondary, 0.78 for Preoccupation with Relationships, and 0.79 for Need for Approval.

\subsubsection{Mental Health}

The Depression, Anxiety, and Stress Scale-21 (DASS-21) was used to assess mental health [29]. This measure has been found to be reliable and valid for the assessment of mental health in the Chinese population [30,31], and it has been applied in studies related to the SARS outbreak [32]. The DASS-21 comprises three self-report scales measuring the emotional states of depression, anxiety, and stress. Each scale contains seven items, divided into subscales with similar content. Items 3, 5, 10, 13, 16, 17, and 21 comprise the Depression subscale (e.g., "In the last 7 days, I couldn't seem to experience any positive feeling at all"; "In the last 7 days, I found it difficult to work up the initiative to do things"); items 2, 4, 7, 9, 15, 19, and 20 comprise the Anxiety subscale (e.g., "In the last 7 days, I experienced trembling"; "In the last 7 days, I was worried about situations in which I might panic and make a fool of myself"); and items 1, 6, 8, 11, 12, 14, and 18 comprise the Stress subscale (e.g., "In the last 7 days, I tended to over-react to situations"; "In the last 7 days, I felt that I was using a lot of nervous energy"). All subscales are rated on a four-point Likert scale ranging from 0 (never) to 3 (almost always). DASS-21 outcome scores are classified into three ranges: average, high, and extremely high. The measure obtained high reliabilities in the Italian validation study [29], with Cronbach's alpha values of $0.74,0.82$, and 0.85 for the Anxiety, Depression, and Stress subscales, respectively; Cronbach's alpha for the total score was 0.90. In the present sample, Cronbach's alpha values were $0.86,0.84$, and 0.90 for the Depression, Anxiety, and Stress subscales, respectively. Cronbach's alpha for the total score was 0.94 .

In the present study, the DASS-21 total and subscale scores were classified as follows: normal for scores within $1 S D$ above the mean and high for scores $>1 S D$ above the mean (see Table S2 in Supplementary Materials).

\subsection{Statistical Analysis}

To address the research questions, we subdivided the sample into two groups, according to normal versus high DASS-21 total and subscale scores (as described in Section 2.3.4). Analyses used standard univariate comparisons of continuous measures (ANOVAs) and 
categorical measures (chi-square tests) to compare factors of interest (i.e., sociodemographic data, PID-5-BF scores, ASQ scores (except for the ASQ Confidence score)) in both groups. For each DASS-21 subscale, factors significantly associated with normal or high levels of distress/depression/anxiety/stress in the bivariate analyses were subsequently analyzed via multiple multivariate logistic regression. This generated odds ratios (ORs) and $95 \%$ confidence intervals (CIs), using normal/high psychological distress/depression/anxiety/stress as dependent outcomes. All statistical analyses were performed using SPSS Statistics 25.0 (IBM SPSS Statistics, New York, NY, USA).

\section{Results}

\subsection{Analysis of Group Differences}

3.1.1. Depression Anxiety Stress Scale-21 Total Score

Table 2 summarizes the statistically significant differences found with respect to the DASS-21 total score. No such differences were observed for educational level $\left(X^{2}=2.35\right.$; $p=0.308)$, employment status $\left(X^{2}=1.79 ; p=0.180\right)$, region of residence $\left(X^{2}=5.40\right.$; $p=0.067)$, infected acquaintances $\left(X^{2}=2.18 ; p=0.140\right)$, history of stressful situations $\left(X^{2}=0.20\right.$; $p=0.653)$, history of medical problems $\left(X^{2}=0.03 ; p=0.863\right)$, spending social distancing period with others or alone $\left(X^{2}=0.02 ; p=0.896\right)$, psychological support or psychotherapy $\left(X^{2}=0.75\right.$; $p=0.385)$, or ASQ Relationships as Secondary $(F=2.12 ; p=0.147)$.

Table 2. Significant differences in sociodemographic and psychometric variables with respect to the DASS-21 total score.

\begin{tabular}{|c|c|c|c|c|c|}
\hline Characteristic & Total & Normal & High & $X^{2}$ or $\mathrm{F}$ & $p$ \\
\hline Gender $(n, \%)$ & & & & 6.91 & 0.009 \\
\hline Female & $228(77)$ & $166(72.8)$ & $62(27.2)$ & & \\
\hline Male & $68(23)$ & $60(88.2)$ & $8(11.8)$ & & \\
\hline Children in house $(n, \%)$ & & & & 8.75 & 0.003 \\
\hline Yes & $98(33.1)$ & $85(86.7)$ & $13(13.3)$ & & \\
\hline No & $198(66.9)$ & $141(71.2)$ & $57(28.8)$ & & \\
\hline Infected loved ones $(n, \%)$ & & & & 5.43 & 0.020 \\
\hline Yes & $23(7.8)$ & $13(56.5)$ & $10(43.5)$ & & \\
\hline No & $273(92.2)$ & $213(78)$ & $60(22)$ & & \\
\hline Marital status $(n, \%)$ & & & & 8.42 & 0.015 \\
\hline Unmarried/widower & $142(48)$ & $98(69)$ & $44(31)$ & & \\
\hline Separated/divorced & $17(5.7)$ & $15(88.2)$ & $2(11.8)$ & & \\
\hline Married & $137(46.3)$ & $113(82.5)$ & $24(17.5)$ & & \\
\hline Age $(M, S D)$ & $38.89(12.32)$ & $40.19(12.53)$ & $34.71(10.68)$ & 10.89 & 0.001 \\
\hline \multicolumn{6}{|l|}{$\operatorname{ASQ}(M, S D)$} \\
\hline Discomfort with Closeness & $31.22(6.85)$ & $30.38(6.60)$ & $33.91(7.00)$ & 14.85 & 0.000 \\
\hline Need for Approval & $18.04(6.59)$ & $16.79(5.73)$ & $22.07(7.57)$ & 38.72 & 0.000 \\
\hline Preoccupation with Relationships & $26.69(7.63)$ & $25.42(7.21)$ & $30.77(7.57)$ & 28.71 & 0.000 \\
\hline \multicolumn{6}{|l|}{ PID-5-BF $(M, S D)$} \\
\hline Negative Affect & $4.34(2.98)$ & $3.70(2.66)$ & $6.40(3.07)$ & 51.26 & 0.000 \\
\hline Detachment & $2.26(2.58)$ & $1.76(2.18)$ & $3.90(3.09)$ & 41.78 & 0.000 \\
\hline Antagonism & $2.51(2.38)$ & $2.27(2.28)$ & $3.27(2.54)$ & 9.70 & 0.002 \\
\hline Disinhibition & $2.57(2.59)$ & $2.38(2.55)$ & $3.16(2.62)$ & 4.83 & 0.029 \\
\hline Psychoticism & $2.79(2.57)$ & $2.31(2.29)$ & $4.31(2.82)$ & 36.38 & 0.000 \\
\hline
\end{tabular}

Abbreviations: $d f=$ degrees of freedom; $X^{2}=$ chi-square test; $\mathrm{F}=$ value of variance of the group means, $p$, statistical significance; ASQ, Attachment Style Questionnaire; PID-5-BF, Personality Inventory for DSM-5-Brief Form-Adult. 


\subsubsection{Depression Anxiety Stress Scale-21 Depression Subscale}

With respect to DASS-21 Depression, Table 3 presents the statistically significant differences found. No such differences were observed for educational level $\left(X^{2}=4.91\right.$; $p=0.086)$, employment status $\left(X^{2}=0.42 ; p=0.515\right)$, region of residence $\left(X^{2}=1.73\right.$; $p=0.421)$, infected acquaintances $\left(X^{2}=3.52 ; p=0.061\right)$, infected loved ones $\left(X^{2}=1.84\right.$; $p=0.175)$, history of stressful situations $\left(X^{2}=0.25 ; p=0.616\right)$, history of medical problems $\left(X^{2}=0.00 ; p=0.955\right)$, spending social distancing period with others or alone $\left(X^{2}=3.22\right.$; $p=0.073)$, or psychological support or psychotherapy $\left(X^{2}=3.64 ; p=0.056\right)$.

Table 3. Significant differences in sociodemographic and psychometric characteristics for DASS-21 depression.

\begin{tabular}{|c|c|c|c|c|c|}
\hline Characteristic & Total & Normal & High & $X^{2}$ or $F$ & $p$ \\
\hline Gender $(n, \%)$ & & & & 5.01 & 0.025 \\
\hline Female & $228(77)$ & $168(73.7)$ & $60(26.3)$ & & \\
\hline Male & $68(23)$ & $59(86.8)$ & $9(13.2)$ & & \\
\hline Children in house $(n, \%)$ & & & & 11.97 & 0.001 \\
\hline Yes & $98(33.1)$ & $87(88.8)$ & $11(11.2)$ & & \\
\hline No & $198(66.9)$ & $140(70.7)$ & $58(29.3)$ & & \\
\hline Marital status $(n, \%)$ & & & & 12.71 & 0.002 \\
\hline Unmarried/widower & $142(48)$ & $96(67.6)$ & $46(32.4)$ & & \\
\hline Separated/divorced & $17(5.7)$ & $15(88.2)$ & $2(11.8)$ & & \\
\hline Married & $137(46.3)$ & $116(84.7)$ & $21(15.3)$ & & \\
\hline Age $(M, S D)$ & $38.89(12.32)$ & $40.30(12.64)$ & $34.28(9.99)$ & 13.15 & 0.000 \\
\hline \multicolumn{6}{|l|}{$\operatorname{ASQ}(M, S D)$} \\
\hline Discomfort with Closeness & $31.22(6.85)$ & $30.15(6.66)$ & $34.72(6.33)$ & 25.51 & 0.000 \\
\hline Relationships as Secondary & $13.95(5.25)$ & $13.44(5.15)$ & $15.61(5.29)$ & 9.26 & 0.003 \\
\hline Need for Approval & $18.04(6.59)$ & $16.75(5.87)$ & $22.26(7.10)$ & 42.07 & 0.000 \\
\hline Preoccupation with Relationships & $26.69(7.63)$ & $25.04(7.13)$ & $32.10(6.70)$ & 53.30 & 0.000 \\
\hline \multicolumn{6}{|l|}{ PID-5-BF $(M, S D)$} \\
\hline Negative Affect & $4.34(2.98)$ & $3.65(2.66)$ & $6.61(2.87)$ & 63.09 & 0.000 \\
\hline Detachment & $2.26(2.58)$ & $1.67(2.13)$ & $4.22(2.98)$ & 61.96 & 0.000 \\
\hline Antagonism & $2.51(2.38)$ & $2.26(2.28)$ & $3.35(2.50)$ & 11.60 & 0.001 \\
\hline Disinhibition & $2.57(2.59)$ & $2.28(2.40)$ & $3.52(2.95)$ & 12.74 & 0.000 \\
\hline Psychoticism & $2.79(2.57)$ & $2.28(2.22)$ & $4.45(2.92)$ & 43.16 & 0.000 \\
\hline
\end{tabular}

Abbreviations: $d f=$ degrees of freedom; $X^{2}=$ chi-square test; $\mathrm{F}=$ value of variance of the group means, $p$, statistical significance; ASQ, Attachment Style Questionnaire; PID-5-BF, Personality Inventory for DSM-5-Brief Form-Adult.

\subsubsection{Depression Anxiety Stress Scale-21 Anxiety Subscale}

Regarding DASS-21 Anxiety, Table 4 presents the statistically significant differences found. No such differences were observed for educational level $\left(X^{2}=3.43 ; p=0.180\right)$, employment status $\left(X^{2}=0.33 ; p=0.568\right)$, region of residence $\left(X^{2}=1.42 ; p=0.493\right)$, infected acquaintances $\left(X^{2}=0.19 ; p=0.666\right)$, infected loved ones $\left(X^{2}=3.48 ; p=0.062\right)$, history of stressful situations $\left(X^{2}=0.11 ; p=0.743\right)$, history of medical problems $\left(X^{2}=1.07\right.$; $p=0.301)$, marital status $\left(X^{2}=5.29 ; p=0.071\right)$, spending social distancing period with others or alone $\left(X^{2}=1.56 ; p=0.211\right)$, psychological support or psychotherapy $\left(X^{2}=1.12 ; p=0.290\right)$, ASQ Relationships as Secondary $(F=0.94 ; p=0.332)$, PID-5-BF Antagonism $(F=2.73$; $p=0.100)$, or PID-5-BF Disinhibition $(F=0.54 ; p=0.462)$.

\subsubsection{Depression Anxiety Stress Scale-21 Stress Subscale}

With respect to DASS-21 Stress, Table 5 summarizes the statistically significant differences found. No such differences were observed for educational level $\left(X^{2}=1.30\right.$; $p=0.521)$, age $(F=3.17 ; p=0.076)$, employment status $\left(X^{2}=1.46 ; p=0.227\right)$, children in house $\left(X^{2}=3.12 ; p=0.077\right)$, region of residence $\left(X^{2}=2.99 ; p=0.223\right)$, infected acquaintances 
$\left(X^{2}=3.17 ; p=0.075\right)$, infected loved ones $\left(X^{2}=2.81 ; p=0.094\right)$, history of stressful situations $\left(X^{2}=0.10 ; p=0.751\right)$, history of medical problems $\left(X^{2}=0.72 ; p=0.398\right)$, marital status $\left(X^{2}=1.95 ; p=0.377\right)$, spending social distancing period with others or alone $\left(X^{2}=1.34\right.$; $p=0.247)$, psychological support of psychotherapy $\left(X^{2}=1.56 ; p=0.211\right)$, or ASQ Relationships as Secondary $(F=1.52 ; p=0.219)$.

Table 4. Significant differences in sociodemographic and psychometric characteristics for DASS-21 anxiety.

\begin{tabular}{|c|c|c|c|c|c|}
\hline Characteristic & Total & Normal & High & $X^{2}$ or $F$ & $p$ \\
\hline Gender $(n, \%)$ & & & & 9.42 & 0.002 \\
\hline Female & $228(77)$ & $182(79.8)$ & $46(20.2)$ & & \\
\hline Male & $68(23)$ & $65(95.6)$ & $3(4.4)$ & & \\
\hline Children in house $(n, \%)$ & & & & 5.76 & 0.016 \\
\hline Yes & $98(33.1)$ & $89(90.8)$ & $9(9.2)$ & & \\
\hline No & $198(66.9)$ & $158(79.8)$ & $40(20.2)$ & & \\
\hline Age $(M, S D)$ & $38.89(12.32)$ & $39.94(12.75)$ & $33.59(8.10)$ & 11.24 & 0.001 \\
\hline \multicolumn{6}{|l|}{$\operatorname{ASQ}(M, S D)$} \\
\hline Discomfort with Closeness & $31.22(6.85)$ & $30.85(6.53)$ & $33.06(8.12)$ & 4.29 & 0.039 \\
\hline Need for Approval & $18.04(6.59)$ & $17.28(6.19)$ & $21.84(7.30)$ & 20.81 & 0.000 \\
\hline Preoccupation with Relationships & $26.69(7.63)$ & $25.99(7.34)$ & $30.20(8.14)$ & 12.97 & 0.000 \\
\hline \multicolumn{6}{|l|}{ PID-5-BF $(M, S D)$} \\
\hline Negative Affect & $4.34(2.98)$ & $3.98(2.79)$ & $6.14(3.31)$ & 23.10 & 0.000 \\
\hline Detachment & $2.26(2.58)$ & $2.03(2.37)$ & $3.43(3.25)$ & 12.37 & 0.001 \\
\hline Psychoticism & $2.79(2.57)$ & $2.61(2.48)$ & $3.69(2.81)$ & 7.50 & 0.007 \\
\hline
\end{tabular}

Abbreviations: $d f=$ degrees of freedom; $X^{2}=$ chi-square test; $\mathrm{F}=$ value of variance of the group means, $p$, statistical significance; ASQ, Attachment Style Questionnaire; PID-5-BF, Personality Inventory for DSM-5-Brief Form-Adult.

Table 5. Significant differences in sociodemographic and psychometric characteristics for DASS-21 stress.

\begin{tabular}{|c|c|c|c|c|c|}
\hline Characteristic & Total & Normal & High & $X^{2}$ or $F$ & $p$ \\
\hline Gender $(n, \%)$ & & & & 4.71 & 0.030 \\
\hline Female & $228(77)$ & $165(72.4)$ & $63(27.6)$ & & \\
\hline Male & $68(23)$ & $58(85.3)$ & $10(14.7)$ & & \\
\hline \multicolumn{6}{|l|}{$\operatorname{ASQ}(M, S D)$} \\
\hline Discomfort with Closeness & $31.22(6.85)$ & $30.56(6.49)$ & $33.23(7.54)$ & 8.58 & 0.004 \\
\hline Need for Approval & $18.04(6.59)$ & $17.00(5.74)$ & $21.22(7.93)$ & 24.36 & 0.000 \\
\hline Preoccupation with Relationships & $26.69(7.63)$ & $25.46(7.19)$ & $30.44(7.75)$ & 25.33 & 0.000 \\
\hline \multicolumn{6}{|l|}{ PID-5-BF $(M, S D)$} \\
\hline Negative Affect & $4.34(2.98)$ & $3.76(2.66)$ & $6.10(3.24)$ & 37.84 & 0.000 \\
\hline Detachment & $2.26(2.58)$ & $1.86(2.27)$ & $3.49(3.07)$ & 23.58 & 0.000 \\
\hline Antagonism & $2.51(2.38)$ & $2.32(2.30)$ & $3.10(2.52)$ & 5.99 & 0.015 \\
\hline Disinhibition & $2.57(2.59)$ & $2.39(2.54)$ & $3.11(2.65)$ & 4.31 & 0.039 \\
\hline Psychoticism & $2.79(2.57)$ & $2.42(2.31)$ & $3.92(2.96)$ & 20.04 & 0.000 \\
\hline
\end{tabular}

Abbreviations: $d f=$ degrees of freedom; $X^{2}=$ chi-square test; $\mathrm{F}=$ value of variance of the group means, $p$, statistical significance; ASQ, Attachment Style Questionnaire; PID-5-BF, Personality Inventory for DSM-5-Brief Form-Adult.

\subsection{Multivariate Logistic Regression}

A multiple logistic regression analysis was performed using the enter method. For the DASS-21 total score, logistic regression identified infected loved ones $(\mathrm{OR}=3.30$; $p=0.24)$ and PID-5-BF Detachment $(\mathrm{OR}=1.24 ; p=0.12)$ as predictors of high levels of psychological distress. Overall, prediction success was $81.8 \%$ (95.1\% for normal and 38.6\% for high classifications). The prediction model showed goodness of fit to the observed data 
$\left(X^{2}=71.34, p=0.000\right)$, and Nagelkerke's $R^{2}$ of 0.322 indicated a moderate relationship between prediction and grouping.

For DASS-21 Depression, logistic regression identified PID-5-BF Detachment $(\mathrm{OR}=1.33 ; p=0.002)$ and ASQ Preoccupation with Relationships $(\mathrm{OR}=1.09 ; p=0.011)$ as predictors of high levels of depression. Overall, prediction success was $82.1 \%(94.7 \%$ for normal and $40.6 \%$ for high classifications). The prediction model showed goodness of fit to the observed data $\left(X^{2}=85.21 ; p=0.000\right)$, and Nagelkerke's $R^{2}$ of 0.378 indicated a moderate relationship between prediction and grouping.

For DASS-21 Anxiety, logistic regression identified gender ( $\mathrm{OR}=4.23 ; p=0.027)$ as a predictor of high levels of anxiety. Overall, prediction success was $84.1 \%$ (98.4\% for normal and $12.2 \%$ for high classifications). The prediction model showed goodness of fit to the observed data $\left(X^{2}=38.66 ; p=0.000\right)$, and Nagelkerke's $R^{2}$ of 0.207 indicated a weak relationship between prediction and grouping.

Finally, for DASS-21 Stress, logistic regression identified BID-5-BF Negative Affect $(\mathrm{OR}=1.17 ; p=0.036)$ as a predictor of high levels of stress. Overall, prediction success was $79.7 \%$ (95.1\% for normal and 32.9\% for high classifications). The prediction model showed goodness of fit to the observed data $\left(X^{2}=43.99 ; p=0.000\right)$, and Nagelkerke's $R^{2}$ of 0.205 indicated a weak relationship between prediction and grouping. Table 6 presents the results of the logistic regressions.

Table 6. Logistic regressions.

\begin{tabular}{|c|c|c|c|}
\hline Variable & OR $[95 \% \mathrm{CI}]$ & Wald & $p$ \\
\hline \multicolumn{4}{|l|}{ DASS-21 Total Score } \\
\hline Gender & $2.23[0.865 .74]$ & 2.76 & 0.097 \\
\hline Age & $0.97[0.931 .02]$ & 1.40 & 0.236 \\
\hline Unmarried/widower [ref. Married] & $1.12[0.502 .52]$ & 0.08 & 0.780 \\
\hline Separated/divorced [ref. Married] & $0.82[0.144 .74]$ & 0.05 & 0.826 \\
\hline Children in house & $1.02[0.343 .08]$ & 0.00 & 0.977 \\
\hline Infected loved ones & $3.30[1.179 .34]$ & 5.08 & 0.024 \\
\hline ASQ Discomfort with Closeness & $0.97[0.911 .03]$ & 0.91 & 0.341 \\
\hline ASQ Need for Approval & $1.02[0.961 .09]$ & 0.45 & 0.502 \\
\hline ASQ Preoccupation with Relationships & $1.02[0.971 .09]$ & 0.64 & 0.424 \\
\hline PID-5-BF Negative Affect & $1.14[0.981 .34]$ & 2.71 & 0.100 \\
\hline PID-5-BF Detachment & $1.24[1.051 .46]$ & 6.27 & 0.012 \\
\hline PID-5-BF Antagonism & $0.97[0.821 .14]$ & 0.14 & 0.705 \\
\hline PID-5-BF Disinhibition & $0.88[0.761 .02]$ & 2.97 & 0.085 \\
\hline PID-5-BF Psychoticism & $1.15[0.961 .38]$ & 2.20 & 0.138 \\
\hline \multicolumn{4}{|l|}{ DASS-21 Depression } \\
\hline Gender & $1.86[0.734 .72]$ & 1.68 & 0.195 \\
\hline Age & $0.98[0.931 .02]$ & 1.04 & 0.309 \\
\hline Unmarried/widower [ref. Married] & $1.00[0.432 .31]$ & 0.00 & 0.998 \\
\hline Separated/divorced [ref. Married] & $0.64[0.104 .11]$ & 0.23 & 0.635 \\
\hline Children in house & $0.65[0.202 .08]$ & 0.52 & 0.470 \\
\hline ASQ Discomfort with Closeness & $0.99[0.931 .07]$ & 0.02 & 0.880 \\
\hline ASQ Relationships as Secondary & $0.99[0.921 .08]$ & 0.02 & 0.888 \\
\hline ASQ Need for Approval & $0.99[0.921 .06]$ & 0.14 & 0.713 \\
\hline ASQ Preoccupation with Relationships & $1.09[1.021 .16]$ & 6.50 & 0.011 \\
\hline PID-5-BF Negative Affect & $1.12[1.021 .16]$ & 1.82 & 0.177 \\
\hline PID-5-BF Detachment & $1.33[1.121 .60]$ & 9.99 & 0.002 \\
\hline PID-5-BF Antagonism & $0.91[0.771 .08]$ & 1.18 & 0.277 \\
\hline PID-5-BF Disinhibition & $0.97[0.841 .12]$ & 0.16 & 0.687 \\
\hline PID-5-BF Psychoticism & $1.06[0.881 .28]$ & 0.33 & 0.566 \\
\hline
\end{tabular}


Table 6. Cont.

\begin{tabular}{cccc}
\hline Variable & OR [95\% CI] & Wald & $p$ \\
\hline DASS-21 Anxiety & & & \\
\hline Gender & $\mathbf{4 . 2 3}[\mathbf{1 . 1 7} \mathbf{1 5 . 2 0}]$ & $\mathbf{4 . 8 7}$ & $\mathbf{0 . 0 2 7}$ \\
Age & $0.97[0.921 .01]$ & 2.32 & 0.128 \\
Children in house & $0.78[0.262 .33]$ & 0.20 & 0.653 \\
ASQ Discomfort with Closeness & $0.97[0.911 .03]$ & 1.06 & 0.302 \\
ASQ Need for Approval & $1.04[0.971 .12]$ & 1.19 & 0.275 \\
ASQ Preoccupation for Relationships & $1.02[0.961 .08]$ & 0.36 & 0.551 \\
PID-5-BF Negative Affect & $1.14[0.961 .35]$ & 2.21 & 0.137 \\
PID-5-BF Detachment & $1.16[0.981 .37]$ & 2.83 & 0.093 \\
PID-5-BF Psychoticism & $0.93[0.781 .11]$ & 0.59 & 0.442 \\
\hline DASS-21 Stress & & & \\
\hline Gender & $1.85[0.834 .14]$ & 2.32 & 0.135 \\
ASQ Discomfort with Closeness & $0.97[0.921 .03]$ & 1.05 & 0.305 \\
ASQ Need for Approval & $1.02[0.971 .09]$ & 0.64 & 0.425 \\
ASQ Preoccupation with Relationships & $1.04[0.991 .10]$ & 2.03 & 0.154 \\
PID-5-BF Negative Affect & $\mathbf{1 . 1 7}[\mathbf{1 . 0 1} 1.36]$ & 4.40 & $\mathbf{0 . 0 3 6}$ \\
PID-5-BF Detachment & $1.14[0.981 .32]$ & 2.76 & 0.097 \\
PID-5-BF Antagonism & $0.96[0.831 .12]$ & 0.25 & 0.619 \\
PID-5-BF Disinhibition & $0.96[0.841 .09]$ & 0.42 & 0.518 \\
PID-5-BF Psychoticism & $1.02[0.861 .21]$ & 0.08 & 0.782 \\
\hline
\end{tabular}

Significant results in bold. Abbreviations: $\mathrm{OR}=$ odds ratio; $\mathrm{CI}=$ confidence interval; $p=$ statistical significance; ASQ = Attachment Style Questionnaire; PID-5-BF = Personality Inventory for DSM-5-Brief Form-Adult.

\section{Discussion}

The present study aimed at investigating the psychological effects of the COVID-19 pandemic on HPs, considering the role of sociodemographic factors, attachment style, and personality dysfunction. The main findings can be summarized as follows: higher stress was associated with negative affect; higher anxiety was associated with female gender; higher depression was associated with detachment and preoccupation with relationships; and higher psychological distress was associated with having an infected loved one and the personality dimension of detachment. In line with the results reported in previous studies [2,33], the present findings underline that higher stress levels are associated with the personality dimension of negative affect. Specifically, higher levels of perceived threat related to the COVID-19 outbreak and low levels of perceived efficacy related to higher levels of stress in participants with strong negative affectivity [34].

The present study also provided empirical support for the association between female gender and anxiety. According to the literature, women tend to be more susceptible to experiencing anxiety, stress, and post-traumatic stress symptoms, relative to men [35]. COVID-19-related studies also found this association in the general population, highlighting that the pandemic tends to have a greater effect, in terms of anxiety, on women [36-38]. Furthermore, the present finding is consistent with the results of previous COVID-19-related studies showing an association, in healthcare workers, between female gender and increased risk for anxiety; as well as increased risk for depression and stress in female healthcare professionals and, specifically, frontline nurses (see $[39,40]$ for systematic reviews).

The present finding of an association between depression and the personality dimension of detachment is in line with the literature [2,41]. It is also not surprising, considering that the PID-5-BF conceptualizes detachment as depressive affect and interpersonal withdrawal, and the trait has been found to be a good index of internalizing psychopathology [42,43]. A recent study [44] found similar results, highlighting that the pathological personality dimensions of negative affectivity and detachment were relevant predictors of clinically significant emotional problems in a sample of Italian community-dwelling adults.

The finding of an association between depression and preoccupation with relationships is also consistent with previous research indicating a link-in both non-clinical and 
clinical samples-between insecure attachment styles and affective disorders, such as depression [45-49].

The present study found psychological distress, as measured by the DASS-12 total score, to be associated with detachment and having an infected loved one. These results suggest that having a relative or close friend infected with COVID-19 is significantly associated with higher levels of psychological distress. This result is consistent with Dong et al.'s [50] finding that having a friend or close relative infected with COVID-19 was the only relative factor contributing to a high Huaxi Emotional-Distress Index (HEI) score. The result is also consistent with the literature on previous epidemics, such as SARS [51]. Finally, the association between detachment and psychological distress is consistent with the results of previous studies finding that internalizing maladaptive personality traits (i.e., detachment, negative affectivity, psychoticism) are strongly associated with psychological distress [52], and that higher levels of detachment and negative affectivity are associated with higher levels of psychological distress. Indeed, internalizing traits might influence subjective sensitivity in the experience of psychological distress. The role of pathological personality domains in individuals' psychological reactions to COVID-19 has been further examined in a recent research study [53], which confirmed their association with negative mental health outcomes during the current pandemic.

Nevertheless, the present study has some limitations, and the results should be interpreted with caution. First, the sample mainly comprised women, thereby reducing the generalizability of the results to women. Second, the survey measure was implemented via the Internet and relied on voluntary sampling and self-reported data. Third, this study used a cross-sectional design, and therefore, it cannot be used to infer causality. A further limitation is that results were not stratified in relation to the different professions of HPs or in relation to being a frontline worker or a general health professional practitioner. Future research should seek to compare the present study data with data collected using other methods (e.g., semi-structured interviews, qualitative approaches). Finally, given the recent resurgence of COVID-19 in the Italian territory [54], it would be useful to conduct further research to identify potential further changes to the psychological wellbeing of HPs at this time, and to guide the development of tailored psychological and psychosocial interventions.

\section{Conclusions}

The aim of the present study was to investigate the psychological effects of the COVID-19 pandemic on HPs, and to assess the role of sociodemographic factors, attachment style, and personality dysfunction.

The pandemic puts an enormous strain on the healthcare system, and HPs must face new challenges (e.g., the constant exposure to COVID-19 patients and the increased workload). One of the contributions of this article is highlighting that the pandemic is taking a toll on the Italian healthcare workforce's mental health. The present results, in fact, suggest that HPs are experiencing high rates of psychological distress-in terms of depression, anxiety, and stress-during the COVID-19 pandemic. Other studies in the Italian context $[55,56]$ also highlighted the need to address this issue, suggesting the implementation of psychoeducational interventions, with the aim to provide support and training for HPs and help them to respond emotionally and psychologically to the COVID-19 pandemic. A further contribution of our research is suggesting that specific factors (i.e., attachment style, personality traits, sociodemographic factors) may be useful in identifying HPs at greatest risk for developing mental health symptoms. Specifically, detachment and preoccupation with relationships were found to be associated with higher levels of depression; having an infected loved one and detachment were found to be associated with higher levels of psychological distress; and being female and negative affect were found to be associated with higher levels of anxiety and stress, respectively. 
Taken together, these findings highlight the need to develop tailored psychological interventions towards vulnerable individuals among the HPs, considering possible risk factors at the individual level.

Supplementary Materials: The following are available online at https: / www.mdpi.com/article/ 10.3390/su13094992/s1, Table S1: Mean and Standard Deviation of DASS-21, ASQ, and PID-5-BF scores, Table S2: DASS-21 Classification Levels.

Author Contributions: Survey conception: P.R., M.C.V., D.M., L.F. and S.F.; online questionnaire implementation: E.R.; data analysis: C.M.; data interpretation: all authors; drafting of the manuscript: M.C., C.M., E.R. and S.D.G. All authors have read and agreed to the published version of the manuscript.

Funding: This research received no external funding.

Institutional Review Board Statement: The study was conducted according to the guidelines of the Declaration of Helsinki, and approved by the Institutional Review Board of the Department of Human Neuroscience, Faculty of Medicine and Dentistry, "Sapienza" University of Rome (IRB-2020-6).

Informed Consent Statement: Informed consent was obtained from all subjects involved in the study.

Data Availability Statement: The dataset used and analyzed in the current study is available from the corresponding author upon reasonable request.

Conflicts of Interest: The authors declare no conflict of interest.

\section{References}

1. Roma, P.; Monaro, M.; Muzi, L.; Colasanti, M.; Ricci, E.; Biondi, S.; Napoli, C.; Ferracuti, S.; Mazza, C. How to Improve Compliance with Protective Health Measures during the COVID-19 Outbreak: Testing a Moderated Mediation Model and Machine Learning Algorithms. Int. J. Environ. Res. Public Health 2020, 17, 7252. [CrossRef]

2. Roma, P.; Monaro, M.; Colasanti, M.; Ricci, E.; Biondi, S.; Di Domenico, A.; Verrocchio, M.C.; Napoli, C.; Ferracuti, S.; Mazza, C. A 2-Month Follow-up Study of Psychological Distress among Italian People during the Covid-19 Lockdown. Int. J. Environ. Res. Public Health 2020, 17, 8180. [CrossRef] [PubMed]

3. Fitzpatrick, K.M.; Harris, C.; Drawve, G. How Bad Is It? Suicidality in the Middle of the COVID-19 Pandemic. Suicide Life Threat. Behav. 2020, 50, 1241-1249. [CrossRef] [PubMed]

4. Gualano, M.R.; Lo Moro, G.; Voglino, G.; Bert, F.; Siliquini, R. Effects of Covid-19 Lockdown on Mental Health and Sleep Disturbances in Italy. Int. J. Environ. Res. Public Health 2020, 17, 4779. [CrossRef] [PubMed]

5. Marchetti, D.; Fontanesi, L.; Mazza, C.; Di Giandomenico, S.; Roma, P.; Verrocchio, M.C. Parenting-Related Exhaustion during the Italian COVID-19 Lockdown. J. Pediatr. Psychol. 2020, 45, 1114-1123. [CrossRef]

6. Wang, Y.; Kala, M.P.; Jafar, T.H. Factors Associated with Psychological Distress during the Coronavirus Disease 2019 (COVID-19) Pandemic on the Predominantly General Population: A Systematic Review and Meta-Analysis. PLoS ONE 2020, 15, e0244630. [CrossRef]

7. Mazza, C.; Ricci, E.; Marchetti, D.; Fontanesi, L.; Di Giandomenico, S.; Verrocchio, M.C.; Roma, P. How Personality Relates to Distress in Parents during the Covid-19 Lockdown: The Mediating Role of Child's Emotional and Behavioral Difficulties and the Moderating Effect of Living with Other People. Int. J. Environ. Res. Public Health 2020, 17, 6236. [CrossRef] [PubMed]

8. Marchitelli, S.; Mazza, C.; Lenzi, A.; Ricci, E.; Gnessi, L.; Roma, P. Weight Gain in a Sample of Patients Affected by Overweight/Obesity with and without a Psychiatric Diagnosis during the COVID-19 Lockdown. Nutrients 2020, $12,3525$. [CrossRef]

9. Vindegaard, N.; Benros, M.E. COVID-19 Pandemic and Mental Health Consequences: Systematic Review of the Current Evidence. Brain Behav. Immun. 2020, 89, 531-542. [CrossRef]

10. Ministero della Salute-Professioni Sanitarie. Available online: http://www.salute.gov.it/portale/temi/p2_4.jsp?lingua= italiano\&area=professioni-sanitarie (accessed on 15 December 2020).

11. Lu, W.; Wang, H.; Lin, Y.; Li, L. Psychological Status of Medical Workforce during the COVID-19 Pandemic: A Cross-Sectional Study. Psychiatry Res. 2020, 288, 112936. [CrossRef]

12. Pappa, S.; Ntella, V.; Giannakas, T.; Giannakoulis, V.G.; Papoutsi, E.; Katsaounou, P. Prevalence of Depression, Anxiety, and Insomnia among Healthcare Workers during the COVID-19 Pandemic: A Systematic Review and Meta-Analysis. Brain Behav. Immun. 2020, 88, 901-907. [CrossRef]

13. Shaukat, N.; Ali, D.M.; Razzak, J. Physical and Mental Health Impacts of COVID-19 on Healthcare Workers: A Scoping Review. Int. J. Emerg. Med. 2020, 13, 40. [CrossRef]

14. Vizheh, M.; Qorbani, M.; Arzaghi, S.M.; Muhidin, S.; Javanmard, Z.; Esmaeili, M. The Mental Health of Healthcare Workers in the COVID-19 Pandemic: A Systematic Review. J. Diabetes Metab. Disord. 2020, 19, 1967-1978. [CrossRef] 
15. Kidd, T.; Hamer, M.; Steptoe, A. Examining the Association between Adult Attachment Style and Cortisol Responses to Acute Stress. Psychoneuroendocrinology 2011, 36, 771-779. [CrossRef]

16. Buelow, S.A.; Lyddon, W.J.; Johnson, J.T. Client Attachment and Coping Resources. Couns. Psychol. Q. 2002, 15, 145-152. [CrossRef]

17. Kanninen, K.; Punamäki, R.-L.; Qouta, S. Personality and Trauma: Adult Attachment and Posttraumatic Distress Among Former Political Prisoners. Peace Confl. 2003, 9, 97-126. [CrossRef]

18. O'Connor, M.; Elklit, A. Attachment Styles, Traumatic Events, and PTSD: A Cross-Sectional Investigation of Adult Attachment and Trauma. Attach Hum. Dev. 2008, 10, 59-71. [CrossRef]

19. Wolfgang, G. Relationships between the Two Dimensions of Adult Attachment Theory and the Five-Factor Theory of Personality. Ph.D. Thesis, University of Akron, Akron, OH, USA, 2004.

20. Ditzen, B.; Schmidt, S.; Strauss, B.; Nater, U.M.; Ehlert, U.; Heinrichs, M. Adult Attachment and Social Support Interact to Reduce Psychological but Not Cortisol Responses to Stress. J. Psychosom. Res. 2008, 64, 479-486. [CrossRef] [PubMed]

21. West, A.L. Associations Among Attachment Style, Burnout, and Compassion Fatigue in Health and Human Service Workers: A Systematic Review. J. Hum. Behav. Soc. Environ. 2015, 25, 571-590. [CrossRef]

22. Oh, E.; Seong, G.M. Nurses' organizational commitment, job satisfaction and job stress according to their adult attachment styles. J. East-West Nurs. Res. 2011, 17, 17-124. [CrossRef]

23. Jeong, E.S.; Kim, J.; Bae, S.Y. Job stress and organizational commitment with regard to adult attachment style of small and medium-sized hospital nurses. Korea J. Hosp. Manag. 2018, 23, 72-86.

24. Hawkins, A.C.; Howard, R.A.; Oyebode, J.R. Stress and Coping in Hospice Nursing Staff. The Impact of Attachment Styles. Psycho-Oncology 2007, 16, 563-572. [CrossRef] [PubMed]

25. Moccia, L.; Janiri, D.; Pepe, M.; Dattoli, L.; Molinaro, M.; De Martin, V.; Chieffo, D.; Janiri, L.; Fiorillo, A.; Sani, G.; et al. Affective Temperament, Attachment Style, and the Psychological Impact of the COVID-19 Outbreak: An Early Report on the Italian General Population. Brain Behav. Immun. 2020, 87, 75-79. [CrossRef]

26. Krueger, R.F.; Derringer, J.; Markon, K.E.; Watson, D.; Skodol, A.E. The Personality Inventory for DSM-5-Brief Form (PID-5-BF)—Adult; American Psychiatric Association: Arlington, VA, USA, 2013.

27. Fossati, A.; Somma, A.; Borroni, S.; Markon, K.E.; Krueger, R.F. The Personality Inventory for DSM-5 Brief Form: Evidence for Reliability and Construct Validity in a Sample of Community-Dwelling Italian Adolescents. Assessment 2017, $24,615-631$. [CrossRef] [PubMed]

28. Fossati, A.; Feeney, J.A.; Donati, D.; Donini, M.; Novella, L.; Bagnato, M.; Acquarini, E.; Maffei, C. On the Dimensionality of the Attachment Style Questionnaire in Italian Clinical and Nonclinical Participants. J. Soc. Pers. Relat. 2003, 20, 55-79. [CrossRef]

29. Bottesi, G.; Ghisi, M.; Altoè, G.; Conforti, E.; Melli, G.; Sica, C. The Italian version of the Depression Anxiety Stress Scales-21: Factor structure and psychometric properties on community and clinical samples. Compr. Psychiatry 2015, 60, 170-181. [CrossRef] [PubMed]

30. Wang, C.; Pan, R.; Wan, X.; Tan, Y.; Xu, L.; Ho, C.S.; Ho, R.C. Immediate Psychological Responses and Associated Factors during the Initial Stage of the 2019 Coronavirus Disease (COVID-19) Epidemic among the General Population in China. Int. J. Environ. Res. Public Health 2020, 17, 1729. [CrossRef]

31. Ho, C.S.; Tan, E.L.; Ho, R.C.; Chiu, M.Y. Relationship of Anxiety and Depression with Respiratory Symptoms: Comparison between Depressed and Non-Depressed Smokers in Singapore. Int. J. Environ. Res. Public Health 2019, 16, 163. [CrossRef]

32. McAlonan, G.M.; Lee, A.M.; Cheung, V.; Cheung, C.; Tsang, K.W.; Sham, P.C.; Chua, S.E.; Wong, J.G. Immediate and Sustained Psychological Impact of an Emerging Infectious Disease Outbreak on Health Care Workers. Can. J. Psychiatry 2007, 52, 241-247. [CrossRef]

33. Flesia, L.; Monaro, M.; Mazza, C.; Fietta, V.; Colicino, E.; Segatto, B.; Roma, P. Predicting Perceived Stress Related to the COVID-19 Outbreak through Stable Psychological Traits and Machine Learning Models. J. Clin. Med. 2020, 9, 3350. [CrossRef]

34. Liu, S.; Lithopoulos, A.; Zhang, C.-Q.; Garcia-Barrera, M.A.; Rhodes, R.E. Personality and Perceived Stress during COVID-19 Pandemic: Testing the Mediating Role of Perceived Threat and Efficacy. Pers. Individ. Dif. 2021, 168, 110351. [CrossRef] [PubMed]

35. Sareen, J.; Erickson, J.; Medved, M.I.; Asmundson, G.J.G.; Enns, M.; Stein, M.; Leslie, W.; Doupe, M.; Logsetty, S. Risk factors for post-injury mental health problems. Depress. Anxiety 2013, 30, 321-327. [CrossRef] [PubMed]

36. Özdin, S.; Bayrak Özdin, Ş. Levels and Predictors of Anxiety, Depression and Health Anxiety during COVID-19 Pandemic in Turkish Society: The Importance of Gender. Int. J. Soc. Psychiatry 2020, 66, 504-511. [CrossRef]

37. Ausín, B.; González-Sanguino, C.; Castellanos, M.Á.; Muñoz, M. Gender-Related Differences in the Psychological Impact of Confinement as a Consequence of COVID-19 in Spain. J. Gend. Stud. 2021, 30, 29-38. [CrossRef]

38. Xiong, J.; Lipsitz, O.; Nasri, F.; Lui, L.M.W.; Gill, H.; Phan, L.; Chen-Li, D.; Iacobucci, M.; Ho, R.; Majeed, A.; et al. Impact of COVID-19 Pandemic on Mental Health in the General Population: A Systematic Review. J. Affect. Disord. 2020, 277, 55-64. [CrossRef]

39. Cabarkapa, S.; Nadjidai, S.E.; Murgier, J.; Ng, C.H. The Psychological Impact of COVID-19 and Other Viral Epidemics on Frontline Healthcare Workers and Ways to Address It: A Rapid Systematic Review. Brain Behav. Immun. Health 2020, 8, 100144. [CrossRef] [PubMed]

40. Paybast, S.; Baghalha, F.; Emami, A.; Koosha, M. The Anxiety Disorder Among the Healthcare Providers During The COVID-19 Infection Pandemic: A Systematic Review. Int. Clin. Neurosci. J. 2020, 7, 115-121. [CrossRef] 
41. Mazza, C.; Ricci, E.; Biondi, S.; Colasanti, M.; Ferracuti, S.; Napoli, C.; Roma, P. A nationwide survey of psychological distress among Italian People during the COVID-19 pandemic: Immediate psychological responses and associated factors. Int. J. Environ. Res. Public Health 2020, 17, 3165. [CrossRef]

42. Anderson, J.L.; Sellbom, M.; Salekin, R.T. Utility of the Personality Inventory for DSM-5- Brief Form (PID-5-BF) in the Measurement of Maladaptive Personality and Psychopathology. Assessment 2018, 25, 596-607. [CrossRef]

43. Hyatt, C.S.; Maples-Keller, J.L.; Crowe, M.L.; Sleep, C.E.; Carter, S.T.; Michopoulos, V.; Stevens, J.S.; Jovanovic, T.; Bradley, B.; Miller, J.D.; et al. Psychometric Properties of the Personality Inventory for DSM-5 -Brief Form in a Community Sample with High Rates of Trauma Exposure. J. Pers. Assess. 2020, 103, 204-213. [CrossRef]

44. Somma, A.; Gialdi, G.; Krueger, R.F.; Markon, K.E.; Frau, C.; Lovallo, S.; Fossati, A. Dysfunctional Personality Features, NonScientifically Supported Causal Beliefs, and Emotional Problems during the First Month of the COVID-19 Pandemic in Italy. Pers. Individ. Dif. 2020, 165, 110139. [CrossRef]

45. Mikulincer, M.; Shaver, P.R. Attachment in Adulthood: Structure, Dynamics, and Change; Guilford Press: New York, NY, USA, 2007; ISBN 9781593854577.

46. Bifulco, A.; Moran, P.M.; Ball, C.; Bernazzani, O. Adult Attachment Style. I: Its Relationship to Clinical Depression. Soc. Psychiatry Psychiatr. Epidemiol. 2002, 37, 50-59. [CrossRef]

47. Bifulco, A.; Moran, P.M.; Ball, C.; Lillie, A. Adult Attachment Style. II: Its Relationship to Psychosocial Depressive-Vulnerability. Soc. Psychiatry Psychiatr. Epidemiol. 2002, 37, 60-67. [CrossRef] [PubMed]

48. Eng, W.; Heimberg, R.G.; Hart, T.A.; Schneier, F.R.; Liebowitz, M.R. Attachment in individuals with social anxiety disorder: The relationship among adult attachment styles, social anxiety, and depression. Emotion 2001, 1, 365. [CrossRef] [PubMed]

49. Miljkovitch, R.; Pierrehumbert, B.; Karmaniola, A.; Bader, M.; Halfon, O. Assessing Attachment Cognitions and Their Associations with Depression in Youth with Eating or Drug Misuse Disorders. Subst. Use Misuse 2005, 40, 605-623. [CrossRef]

50. Dong, Z.-Q.; Ma, J.; Hao, Y.-N.; Shen, X.-L.; Liu, F.; Gao, Y.; Zhang, L. The Social Psychological Impact of the COVID-19 Pandemic on Medical Staff in China: A Cross-Sectional Study. Eur. Psychiatr. 2020, 63, e65. [CrossRef]

51. Wu, P.; Fang, Y.; Guan, Z.; Fan, B.; Kong, J.; Yao, Z.; Liu, X.; Fuller, C.J.; Susser, E.; Lu, J.; et al. The Psychological Impact of the SARS Epidemic on Hospital Employees in China: Exposure, Risk Perception, and Altruistic Acceptance of Risk. Can. J. Psychiatry 2009, 54, 302-311. [CrossRef] [PubMed]

52. Benzi, I.M.A.; Preti, E.; Di Pierro, R.; Clarkin, J.F.; Madeddu, F. Maladaptive Personality Traits and Psychological Distress in Adolescence: The Moderating Role of Personality Functioning. Pers. Individ. Dif. 2019, 140, 33-40. [CrossRef]

53. Zemestani, M.; Babamiri, M.; Griffiths, M.D.; Didehban, R. DSM-5 Pathological Personality Domains as Vulnerability Factors in Predicting COVID-19-Related Anxiety Symptoms. J. Addict. Dis. 2021, 1-14. [CrossRef]

54. Protezione Civile. 2020. Available online: http:// opendatadpc.maps.arcgis.com/apps/opsdashboard/index.html\#/b0c68bce2 cce478eaac82fe38d4138b1 (accessed on 20 October 2020).

55. Buselli, R.; Baldanzi, S.; Corsi, M.; Chiumiento, M.; Del Lupo, E.; Carmassi, C.; Dell'Osso, L.; Cristaudo, A. Psychological Care of Health Workers during the COVID-19 Outbreak in Italy: Preliminary Report of an Occupational Health Department (AOUP) Responsible for Monitoring Hospital Staff Condition. Sustainability 2020, 12, 5039. [CrossRef]

56. Maldonato, N.M.; Bottone, M.; Chiodi, A.; Continisio, G.I.; De Falco, R.; Duval, M.; Muzii, B.; Siani, G.; Valerio, P.; Vitelli, R.; et al. A Mental Health First Aid Service in an Italian University Public Hospital during the Coronavirus Disease 2019 Outbreak. Sustainability 2020, 12, 4244. [CrossRef] 